\title{
PERENCANAAN PONDASI BORE PILE PADA PROYEK JEMBATAN NGUJANG II KAB.TULUNGAGUNG
}

\author{
Heri Wahyudiono ${ }^{1}$, Sulik Anam ${ }^{2}$ \\ ${ }^{1,2}$ Fakultas Teknik Universitas Kadiri \\ e-mail : heri_wahyudiono@unik-kediri.ac.id, sulik_anam@unik-kediri.ac.id
}

\begin{abstract}
The method used in analyzing the foundation of this research is the Mayerhof method and the RSNI-T-022015 based approach to standard loading for bridges, thus obtaining a total vertical load of 770,121 tons, using a bore foundation $80 \mathrm{~cm}$ in diameter with the mayerhof method number of poles 15 with a distance of 2 meters, so the bearing capacity of the foundation pile group: Qug 852,1889 tons $>$ from the load carried (Pu) 770,121 tons (okay), one-way control conditions $\varphi V c$ shear force, 6754,405>Vu, shear strength concrete, 369,490 (okay), two-way control conditions, cVc shear force, 9885.9 tons $>V c$ concrete shear strength 5088,825 tons (okay), reinforcement bore pile foundation. Vc. Shear force 48,593 $<\Phi * V c$ concrete shear resistance 60,625 (okay) the number of staple reinforcement needed 21 d19 and stirrup reinforcement d13, according to the calculation, 15 bore piles are able to withstand the burdens of the upper bridge structure.
\end{abstract}

Keywords: bore pile foundation of the mayerhof method

\begin{abstract}
ABSTRAK
Metode yang di pergunakan dalam melakukan analisa pada pondasi pada penelitian ini adalah metode Mayerhof dan pendekatan berdasarkan RSNI-T-02-2015 tentang standar pembebanan untuk jembatan , maka didapat total beban vertikal 770,121 ton, menggunakan pondasi bore diameter $80 \mathrm{~cm}$ dengan metode mayerhof jumlah tiang 15 dengan jarak 2 meter, jadi daya dukung tanah pondasi tiang kelompok: Qug 852,1889 ton > dari beban yang di pikul (Pu )770,121 ton(oke),control satu arah syarat $\varphi V c$ gaya geser, 6754,405 > Vu,kuat geser beton,369,490 (oke),kontrol dua arah syarat , $\varphi V_{c}$ gaya geser, 9885,9 ton > Vc kuat geser beton 5088,825 ton (oke), tulangan pondasi bore pile. $V c$. gaya geser 48,593 $<\Phi^{*} V c$ tahanan geser beton 60,625 (oke) jumlah tulangan pokok yang dibutuhkan 21 d19 dan tulangan sengkang d13, sesuai perhitungan dengan 15 bore pile mampu menahan beban - beban struktur atas jembatan.
\end{abstract}

Kata Kunci: pondasi bore pile metode mayerhof

\section{PENDAHULUAN}

\subsection{Latar Belakang}

Sebagai permasalahan dalam bidang transportasi tidak bisa di remehkan karena hal ini berkaitan erat dengan perekonomian, sehingga diperlukan solusi yang tepat guna ada banyak alternatif penyelesaian dalam permasalahan transportasi, salah satunya adalah dengan pembangunan jembatan Ngujang II. Proyek Jalur lingkar Timur ( JLT ) melewati kota Tulunggagunng dan kota Kediri , berlokasi di daerah Tulunggung . Jembatan Ngujang II ini sangat penting dalam memecahkan kemacetan lalulintas di Jembatan Ngujang I. Adalah suatu suatu struktur 
bangunan yang termasuk struktur bangunan jembatan, dimana juga memiliki bagian bagian yang sama dengan jembatan.Seperti utama, bangunan bawah, bangunan atas dan berbagai kelengkapan lainnya.

\subsection{Identifikasi Masalah}

Di dalam setiap pembangunan selalu di cari kemudahan dalam pelaksanaanya, Pada proyek jembatan ngujang II daya dukung satu pier yang dibutuhkan sangat besar. Maka Jembatan menggunakan pondasi dalam, digunakan adalah Pondasi Bore Pile. Perencanaan pondasi dalam adalah lokasi yang di kerjakan menghubungkan Kediri-Tulunggung

\section{METODE PENELITIAN}

\subsection{Pondasi}

Pondasi dapat didefinisikan sebaga bangunan bawah dan tanah /atau batuan disekitarnya yang akan dipengaruhi oleh elemen bangunan bawah dan bebannya. Dalam ilmu teknik sipil, keamanan sebuah bangunan sangat ditentukan oleh kekuatan strukturnya, baik struktur atas (upper structure) dan struktur bawah(base structure). Yang dimaksud dengan struktur bawah adalah bagian bangunan yang berada di bawah permukaan tanah. Bangunan struktur bawah ini konstruksi perletakannya disebut dengan fondasi. Banyak jenis pondasi yang dapat digunakan, akan tetapi dalam penentuan jenis fondasi yang akan digunakan tergantung dari kebutuhan, yaitu berdasarkan besar beban yang akan diterima dan jenis lapisan tanah yang digunakan sebagai tempat perletakan pondasi.

\subsection{Acuan Perencanaan}

Perencanaan, pedoman yang digunakan menggunakan literatur buku buku dan tata cara perencanaan untuk jalan raya.

\subsection{Peraturan Perencanaan}

Jika kita merencanakan suatu bangunan kita sudah tentu kita harus memperhatikan segala aspek yang berhubungan dengan bangunan tersebut.Harus sesuai dengan pemahaman buku buku yang ada.

\subsection{Peraturan Perhitungan Konstruksi}

Peraturan perhitungan konstruksi antara lain, Peraturan Perencanaan pembebanan untuk jalan raya. 


\subsection{Dasar Perhitungan Konstruksi}

Dasar perhitungannya yaitu Konstruksi diperhitungkan terhadap pembebanan perhiitungan kontruksi antara lain.peraturan perencanaan pembebanan untuk jalan raya Dan buku -buku

\subsection{Spesifikasi Teknik}

Spesifikasi tekniknya meliputi fc' $=30 \mathrm{MPa}$ dan fy $=240 \mathrm{Mpa}$

Tuntutan dan Ketentuaan Umum Perencanaan

Perencanaan Jembatan harus kita perhatikan antara lain, Konstruksi harus aman, kokoh, kuat, Dari biaya, bangunan harus hemat dan efisien catatan tidak boleh mengurangi kekuatan konstruksi, agar tidak membahayakan bangunan dan keselamatan pengguna bangunan.

\subsection{Pembebanan}

Dalam perencanaan struktur atas perlu memperhatikan beban yang terjadi, antara lain Peraturan Pembebanan, peraturan perencanaan pembebanan untuk jalan raya

Macam Pembebanan

Beban Mati

Beban yang berasal dari berat sendiri jembatan atau bagian jembatan yang di tinjau termasuk segala unsur tambahan tetap yang di anggap merupakan ke- satuan tetap dengan nya.

Beban Hidup

Beban hidup adalah semua beban hidup yang berasal dari berat kendaraan - kendaraan yang bergerak ( Lalu Lintas ) atau berat orang -orang yang berjalan kaki di anggap bekerja pada jembatan. Beban hidup diatas lantai kendaraan di nyatakan dalam dua macam yaitu beban .

Beban Yang Diperhitungkan

Pembebanan diperhitungkan sesuai dengan fungsi bangunan yang direncanakan. Perencanaan beban hidup maupun beban mati didasarkan pada tatacara pembebanan untuk perencanaan untuk jalan raya .

\subsection{Metode Perhitungan}

Perhitungan pembebanan untuk jalan raya (RSNI T-02-2005) sedangkan untuk perhitungan pondasi ( Agatha Iwan Candra.)2017" Materi Kuliah Rekayasa Pondasi II" Universitas Kadiri dan (Pamungkas .Anugrah;Harianti Erny.2013.Desain Pondasi Tahan Gempa Yogyakarta). Hadiyatmo,H.C.2010, 


\subsection{Alur Penelitian}

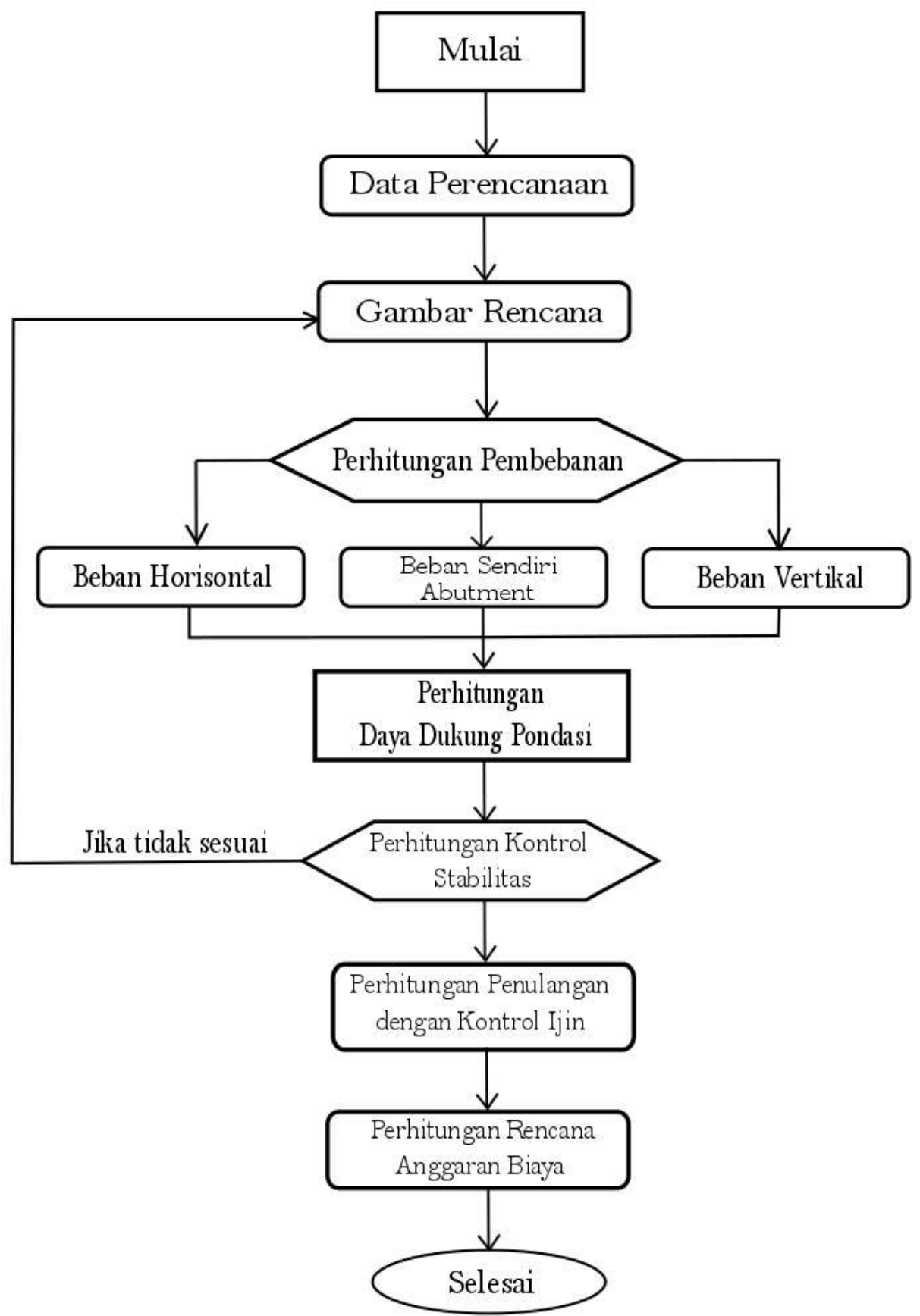

Gambar 1: Alur Penelitian 


\section{HASIL DAN PEMBAHASAN}

Beban Mati $=770,1213$ ton

Beban Hidup $=10$ ton

Metode Mayerhof =57,1675 ton

Hasil analisis daya dukung pondasi dangkal dengan metode Meyerhoff (1976) dapat dilihat pada tabel 1 berikut ini :

Tabel 1. Daya Dukung Pondasi

\begin{tabular}{|c|c|c|c|}
\hline Kedalaman & Lebar Pondasi (B) & Tanahan Konus (qc) & Daya Dukung Pondasi ( $\left.\mathrm{q}_{\text {ult }}\right)$ \\
\hline Pondasi $(\mathrm{cm})$ & $(\mathrm{cm})$ & $(\mathrm{kg} / \mathrm{cm} 2)$ & 260 \\
\hline 60 & 100 & 65 & 275 \\
\hline 100 & 100 & 55 & 260 \\
\hline 160 & 100 & 40 & 188 \\
\hline 200 & 100 & 25 & \\
\hline
\end{tabular}

Hasil analisis daya dukung pondasi tiang dengan metode Meyerhoff (1956) dapat dilihat pada tabel 4 berikut ini :

Tabel 4. Daya Dukung Pondasi Tiang (Meyerhoff)

\begin{tabular}{|c|c|c|c|c|c|c|c|}
\hline Kedalaman & $0(0,0)$ & $\begin{array}{c}\text { Kapaitas Tiang } \\
F_{a} \|(k g)\end{array}$ & 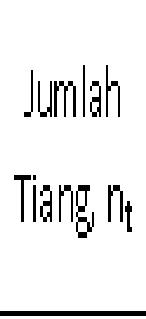 & $\begin{array}{l}\text { Efisientsi } \\
\text { Gitup, E }\end{array}$ & $\begin{array}{l}\text { Kapastas } \\
\text { Kelompok } \\
\text { Tiang } \mathrm{P}\end{array}$ & $\begin{array}{l}P_{\text {IIII }} \\
\text { (Torn) }\end{array}$ & $P_{g}>P_{\pi}$ \\
\hline 3 & 30 & 3308293 & 3 & 0,72 & 71,20 & 69,42 & 0 \\
\hline 4,010 & 30 & 42095,30 & 2 & 0,80 & 73,99 & 69,42 & 0 \\
\hline آل10, & 30 & 48270,57 & 2 & 0,80 & 84,85 & 69,42 & ok \\
\hline
\end{tabular}

Kontrol gaya geser satu arah $\varphi \mathrm{Vc}=6754,405$ ton $>\mathrm{Vu}=369,490$ ton (Oke)

Kontrol gaya geser dua arah $\varphi \mathrm{Vc}=98855,9$ ton $>\mathrm{Vu}=5088,825$ ton (Oke)

Pondasi bore pile yang di butuhkan $(\mathrm{n})=15$ buah

Tulangan pokok 21 - D19 sengkang D13

Kontrol gaya geser $\mathrm{Vu}=48,593<\Phi^{*} \mathrm{Vc}=60,625(\mathrm{Oke})$ 


\section{PENUTUP}

\subsection{Kesimpulan}

Dari hasil analisa perhitungan perencanaan pondasi bore pile jembatan Ngujang II dapat di simpulkan bahwa :

1. Beban yang bekerja $\operatorname{pada}(\mathrm{Pu})=770,1213$ ton yang terdiri dari beban mati dan beban hidup.

2. Berdasarkan perhitungan daya dukung dengan metode Mayerhof (Qall) $=57,1675$ ton

3. Berdasarkan perhitungan kontrol

a. Hasil hitungan kontrol gaya geser satu arah $\varphi \mathrm{Vc}=6754,405$ ton $>\mathrm{Vu}=369,490$ ton (Oke)

b. Hasil hitunngan kontrol gaya geser dua $\operatorname{arah} \varphi \mathrm{Vc}=98855,9$ ton $>\mathrm{Vu}=5088,825$ ton (Oke)

4. Berdasarkan perhitungan

a. Hasil hitungan pondasi bore pile yang di butuhkan $(n)=15$ buah

b. Hasil hitungan tulangan pondasi bore pile tulangan pokok 21 - D19 sengkang D13

c. Hasil hitungan kontrol gaya geser $\mathrm{Vu}=48,593<\Phi^{*} \mathrm{Vc}=60,625$ (Oke)

\subsection{Saran}

Dari analisa perhitungan dan kesimpulan di atas, penulis dapat berikan saran yaitu sebagai berikut :

1. Persiapkan data teknis yang lengkap, berguna untuk menunjang dalam membuat rencana analisa perhitungan,sesuai dengan kriteria perencana.

2. Diharapakan adanya perencanaan bore pile menggunakan diameter yang besar, agar kedalaman tidak terlalu besar' karena bore pile membutuhkan waktu yang lama dalam pekerjaanya.

3. Diharapkan dalam perencaan, pemilihan mutu material dilakukan lebih teliti lagi untuk mendapatkan hasil yang lebih efisien.

\section{DAFTAR PUSTAKA}

[1] ( Ir.H.J.Struyk ,Prof. Ir.K.H.C.W.van der Ven Soemargo , 1984 )

[2] Agata Iwan Candra. “ Universitas Kadiri

[3] Candra, A I, S W Mudjanarko, and Arthur Daniel Limantara. 2017. "Manajemen Data Lalu Lintas Kendaraan Berbasis Sistem Internet Cerdas Kadiri.” Semnastek 4 (2): 1-2. jurnal.umj.ac.id/index.php/semnastek. 
[4] Hadiyatmo, H.C. 2010. Analisis dan Desain Foundasi Bagian II. Gadjah Mada University press, Yogyakarta

[5] 4 Pamungkas. Anugrah ; Harianti. Erny.2013.Desain Pondasi Tahan Gempa Yogyakarta

[6] Bowles, joseph E.1986. Analisa Dan Disain Pondasi Jilid 2 ; Erlangga,

[7] Surendro,Bambang.2015.Rekayasa Fondasi Teori Dan Penyelesaian Soal.Yogyakarta:Graha ilmu

[8] Badan Standarisasi Nasional. 2005. RSNI T-02-2005.

[9] Ma'arif.faqih.2012.Analisis Strukur Jembatan .Yogyakarta; Universitas Negri Yogyakarta

[10] Sardjono H.S., 1988. Pondasi Tiang Pancang Jilid I, Sinar Wijaya, Surabaya.

[11] Bowless, J.E., 1988, Analisis dan Desain Pondasi Edisi Keempat Jilid 2, Erlangga, Jakarta

[12] A., Hanggoro Tri Cahyo, 2006, Hand Out Rekayasa Pondasi 2, Pondasi Tiang Pancang, Jurusan Teknik Sipil - FT Universitas Negeri Semarang

[13] Arifin, Zainul, 2007, Komparasi Daya Dukung Aksial Tiang Tunggal Dihitung dengan Beberapa Metode Analisis, Tesis, Program Pasca Sarjana, Universitas Diponegoro Semarang

[14] Tambunan, Jhonson, 2012, Studi Analisis Daya Dukung Pondasi Tiang

Pancang, Jurnal Rancang Sipil, Vol. 1, No. $1: 21-30$

[15] Fahrani, Ferra dan Apriyanti, Yayuk, 2015, Analisis Daya Dukung Tanah dan Penurunan Pondasi Pada Daerah Pesisir Pantai Utara Kabupaten Bangka, Jurnal Fropil, Vol. 3, No. $2: 89-95$

[16] Candra, A. I. (2017). ANALISIS DAYA DUKUNG PONDASI STROUS PILE 
PADA PEMBANGUNAN GEDUNG MINI HOSPITAL UNIVERSITAS KADIRI. Ukarst, 1(1), 63-70.

[17] Utomo, P. (2004). Daya Dukung Ultimit Pondasi Dangkal Di Atas Tanah Pasir Yang Diperkuat Geogrid. Civil engineering dimension, 6(1), 15-20.

[18] Widjaja, B. (2006). Kajian Pengaruh Setup pada Tiang Pancang terhadap Peningkatan Daya Dukung Pondasi (Studi Kasus Porto dan Jakarta). Jurnal Teknik Sipil Unika Soegijapranata, 3(1), 16-26. 